\title{
ANALISIS PENGARUH GAYA KEPEMIMPINAN DAN KOMPENSASI TERHADAP KINERJA KARYAWAN (STUDI KASUS PADA PT. FINANSIA MULTI FINANCE CABANG BANJARMASIN)
}

\section{Nurul Hasanah}

Fakultas Ekonomi Uniska Banjarmasin

Jl. Adhyaksa No. 2 Kayu Tangi Banjarmasin Kalimantan Selatan

e-mail: nurultata88@gmail.com

\begin{abstract}
This study discusses how human resources in organizational activities in creditplus financing company that is PT. Finansia Multi Finance Branch Banjarmasin to be able to survive in the face of competition and market demands. This research is a quantitative research that is explanatory research that is research to test hypothesis among variables. Population in this research is all employees of PT. Finansia Multi Finance Branch Banjarmasin which amounted to 60 people. The results of the study found that leadership style and compensation partially and simultaneously have an effect on employee performance.
\end{abstract}

Keywords: leadership style, compensation, employee performance

\begin{abstract}
Abstrak
Penelitian ini membahas bagaimana sumber daya manusia dalam kegiatan organisasi pada perusahaan pembiayaan kreditplus yaitu PT. Finansia Multi Finance Cabang Banjarmasin agar mampu bertahan dalam menghadapi persaingan dan tuntutan pasar. Penelitian ini merupakan penelitian kuantitatif yang bersifat penelitian eksplanatory yaitu penelitian untuk menguji hipotesis antar variabel. Populasi pada penelitian ini adalah seluruh karyawan PT. Finansia Multi Finance Cabang Banjarmasin yang berjumlah 60 orang. Hasil penelitian menemukan bahwa gaya kepemimpinan dan kompensasi secara parsial dan simultan berpengaruh terhadap kinerja karyawan.
\end{abstract}

Kata kunci:gaya kepemimpinan, kompensasi, kinerja karyawan

\section{PENDAHULUAN}

Salah satu aspek yang penting dan utama dalam mensukseskan organisasi adalah sumber daya manusia (karyawan). Karyawan adalah aset berharga bagi sebuah perusahaan. Apa yang diberikan karyawan kepada organisasi sangat tergantung pada bagaimana organisasi tersebut memperlakukan, memimpin dan mengatur mereka. Tujuan organisasi tidak akan tercapai dengan baik dan lancar apabila organisasi tidak memperhatikan karyawannya. Perhatian organisasi terhadap karyawan tidak hanya diwujudkan dalam interaksi antara seorang pemimpin dengan bawahan, tetapi juga pada bagaimana kebutuhan dan harapan karyawan dapat terpenuhi oleh organisasi tersebut.

Dalam organisasi ada dua pihak yang saling tergantung dan merupakan unsur utama dalam organisasi yaitu pemimpin sebagai atasan, dan pegawai sebagai bawahan (Mulyadi dan Rivai, 2009). Kepemimpinan pemimpin dalam suatu organisasi dirasa sangat penting, karena pemimpin memiliki peranan yang strategis dalam mencapai tujuan organisasi yang biasa 
tertuang dalam visi dan misi organisasi. Kemudian elemen yang bernilai penting dalam organisasi selain gaya kepemimpinan adalah kompensasi dan efektivitas pelatihan. Kompensasi berkaitan dengan bagaimana perusahaan menghargai hasil kerja dari para pekerja atau karyawan dalam melaksanakan pekerjaannya.

PT. Finansia Multi Finance di Kota Banjarmasin adalah salah satu perusahaan yang bergerak di bidang pendanaan, yang memiliki kegiatan pemberian kredit pendanaan dan pembiayaan. Perusahaan ini dituntut untuk lebih profesional dan mampu bertahan dalam menghadapi persaingan dan tuntutan pasar. Dimana untuk mendukung pelaksanaan tugas-tugas yang ada setiap karyawan harus senantiasa memiliki pemahaman yang baik terhadap apa yang telah menjadi tugas dan tanggung jawabnya masing-masing. Hal ini masih belum sepenuhnya dapat dilakukan karyawan yang masih memerlukan arahan dari pimpinanya untuk dapat mengerjakan tugas-tugasnya dengan baik. Disamping itu, selain dengan gaya kepemimpinan, kompensasi juga sangat berhubungan erat dengan hasil kerja karyawan.

Berdasarkan uraian di atas maka dalam penelitian ini penulis tertarik untuk melakukan penelitian dengan judul analisis pengaruh gaya kepemimpinan dan kompensasi terhadap kinerja karyawan (studi kasus pada PT. Finansia Multi Finance Cabang Banjarmasin).

\section{TINJAUAN PUSTAKA}

Menurut Hasibuan

(2007)

kepemimpinan adalah proses mempengaruhi orang lain untuk memahami dan setuju tentang apa yang akan dikerjakan dan bagaimana tugas itu dapat dilakukan secara efektif, dan proses memfasilitasi usaha individu dan kelompok untuk mencapai tujuan bersama.Mulyadi dan Veithzal Rivai (2009) menerangkan bahwa gaya kepemimpinan merupakan pola perilaku dan strategi yang disukai dan gaya kepemimpinan adalah pola tingkah laku yang dirancang sedemikian rupa untuk mengintegrasikan sering diterapkan oleh seorang pemimpin dalam rangka mencapai sasaran organisasi.

Dessler (1992) mengatakan kompensasi merupakan semua bentuk upah atau imbalan yang berlaku dan muncul dari pekerjaan seseorang, yang mempunyai dua komponen utama yaitu pembayaran keuangan langsung dalam bentuk upah/gaji, insentif, komisi dan bonus serta pembayaran yang tidak langsung seperti dalam bentuk tunjangan keuangan misalnya asuransi dan uang liburan. Definisi yang sama juga dikemukakan oleh Henry (1999, dalam Aunillah 2005) bahwa bentuk kompensasi dapat berupa asuransi jiwa, asuransi kesehatan, dana pensiun, program liburan dan bentuk imbalan lainnya.

Mathis dan Jackson (2002, dalam Faisal, 2005 dalam Husni saleh Maga, 2007) membagi kompensasi dalam dua komponen yaitu kompensasi langsung, yang terdiri dari gaji pokok yaitu upah dan gaji gaji serta gaji variabel yaitu bonus, insentif dan kepemilikan saham, sedangkan kompensasi tidak langsung terdiri dari tunjangan yaitu asuransi kesehatan, asuransi jiwa, libur pengganti, dana pensiun dan kompensasi pekerja.

Menurut Dessler (2006) kinerja pegawai merupakan prestasi kerja, yakni perbandingan antara hasil kerja yang dapat dilihat secara nyata dengan standar kerja yang telah ditetapkan organisasi. Desler (2006) menyebutkan bahwa pengukuran kinerja dilakukan dengan menggunakan kriteria sebagai berikut:

1) Kualitas kerja. Berkaitan dengan 
ketepatan, keterampilan, ketelitian, kecepatan, kecakapan dan kerapian pelaksanaan pekerjaan serta pemeliharaan alat-alat perusahaan.

2) Kuantitas kerja. Berkaitan dengan kemampuan secara kuantitas dalam mencapai target atau tugas-tugas baru.

3) Keandalan. Merupakan kemampuan secara kuantitas dalam mencapai target atau tugas-tugas baru.

4) Efektifitas. Tingkat sumber daya organisasi (tenaga, uang, teknologi, bahan baku) dimaksimalkan dengan maksud menaikkan keuntungan atau mengurangi kerugian dari setiap unit dalam penggunaan sumber daya.

5) Kemandirian. Tingkat seorang karyawan dapat melakukan fungsi kerjanya tanpa meminta bimbingan dari pengawas guna menghindari hasil yang merugikan.

6) Hubungan interpersonal atau kerjasama. Merupakan ukuran bagaimana pegawai menyelesaikan pekerjaan dengan bekerja sama dengan pegawai lain untuk mencapai tujuan organisasi.

\section{METODE PENELITIAN}

Penelitian ini bersifat sebagai penelitian penjelasan (explanatory research). Dalam penelitian ini peneliti ingin menguji pengaruh secara parsial dan simultan gayakepemimpinan dan kompensasi terhadap kinerja karyawanPT Finansia Multi Finance Cabang Banjarmasin. Dalam penelitian ini teknik penentuan sampel menggunakan sampel jenuh sebanyak 60 orang. Sampel jenuh menurut Sugiyono (2008) adalah teknik penentuan sampel bila semua anggota populasi digunakan sebagai sampel. Dalam penelitian ini penentuan sampel jenuh dilakukan agar membuat generalisasi dengan kesalahan yang sangat kecil.

\section{Uji instrumen data:}

1. Uji Validitas

2. Uji Reliabilitas

3. Uji Asumsi Klasik

Uji Normalitas

Uji Multikolinearitas.

Uji Heteroskedastisitas

\section{Analisis Regresi Berganda}

Bentuk regresi linear berganda adalah:

$$
\mathrm{Y}=\mathrm{a}+\mathrm{b} 1 \mathrm{X} 1+\mathrm{b} 2 \mathrm{X} 2+\mathrm{e}
$$

Pengujian Hipotesis

1. Uji Hipotesis (Uji t/pengujian hipotesis secara parsial)

2. Uji Hipotesis(Uji F/uji hipotesis secara simultan)

3. Koefisien Determinasi $\left(\mathrm{R}^{2}\right)$

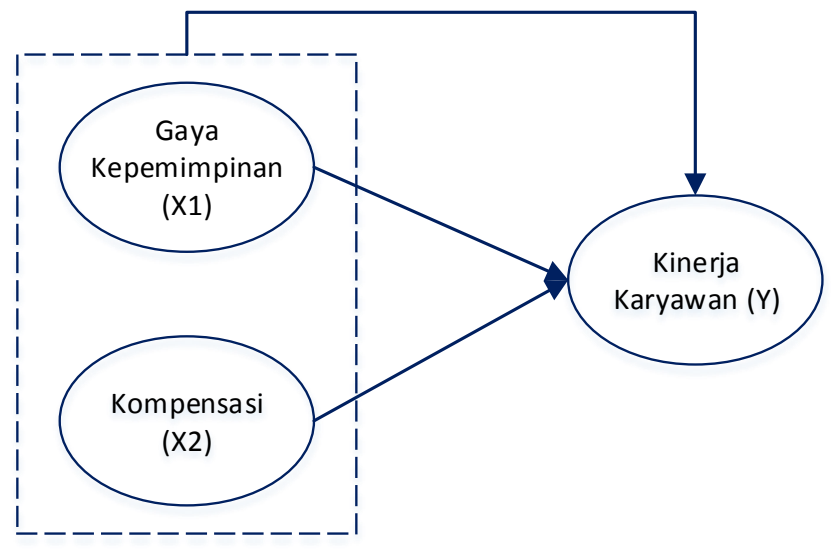




\section{HASIL DAN PEMBAHASAN}

Penelitian dilakukan dengan jumlah responden sebanyak 60 orang karyawan. Analisis data dimulai dengan melakukan uji validitas dan uji reliabilitas instrumen. Hasil pengujian menunjukkan bahwa semua data yang digunakan dalam penelitian ini dinyatakan valid dan reliabel. Ini artinya data yang digunakan dalam penelitian ini tidak bermakna ganda dan sesuai dengan apa yang ingin diukur.

Hasil deskripsi variabel menunjukkan bahwa pada PT. Finansia Multi Finance Cabang Banjarmasin, dari usur yang diteliti yaitu gaya kepemimpinan, kompensasi, dan kinerja karyawan memiliki rata-rata penilaian masing-masing variabel menunjukkan nilai diatas 3. Temuan awal ini memperkuat dugaan bahwa dengan gaya kepemimpinan dan kompensasi yang baik serta efektivitas pelatihan yang sesuai dengan penempatan kerja karyawan maka kienerja karyawan juga akan semakin baik. Selengkapnya dapat dilihat dari uji asumsi klasik, analisis regresi berganda dan pengujian hipotesis.

\section{Uji Asumsi Klasik}

a. Uji multikolinearitas

Multikolinearitas adalah tidak adanya hubungan linier yang sempurna atau pasti antara variabel bebas. Untuk melihat ada atau tidaknya gejala Multikolinearitas dapat diidentifikasi denga melihat nilai VIF (Variance Inflating Factor). Apabila nilai VIF lebih kecil dari 10 dan nilai toleransinya di atas 0,1 atau $10 \%$ maka dapat disimpulkan bahwa model regresi tersebut tidak terjadi multikoliniaritas (Ghozali, 2005). Berdasarkan data dalam tabel 1 menunjukkan bahwa nilai VIF masing-masing variabel bebas lebih kecil dari 10, sehingga dapat dikatakan tidak terjadi gejala multikolinearitas. Hasil pengujian disajikan dalam tabel 1 berikut:

Tabel 1 Hasil Uji Multikolinearitas

\begin{tabular}{|l|c|c|}
\hline \multicolumn{1}{|c|}{ Variabel } & $\begin{array}{c}\text { Nilai } \\
\text { Tolerance }\end{array}$ & VIF \\
\hline Gaya Kepemimpinan & 0,745 & 1,342 \\
\hline Kompensasi & 0,816 & 1,226 \\
\hline
\end{tabular}

Sumber: Data Penelitian, 2017 (telah diolah)

\section{b. Uji Heterokedastisitas}

Model regresi yang baik adalah tidak terjadi heterokedastisitas. Untuk mendeteksi ada tidaknya heterokedastisitas dapat digunakan metode grafik Scatterplot yang dihasilkan dari output program SPSS versi 21, Apabila pada gambar menunjukkan bahwa titik-titik menyebar secara acak serta tersebar baik diatas maupun di bawah angka 0 pada sumbu $\mathrm{Y}$, maka hal ini dapat disimpulkan tidak terjadi adanya heterokedastisitas pada model regresi (Ghozali,2005). Hasil uji homoskedastisitas (atau tidak adanya gejala heteroskedastisitas) diperlihatkan pada Gambar 1. 
Scatterplot

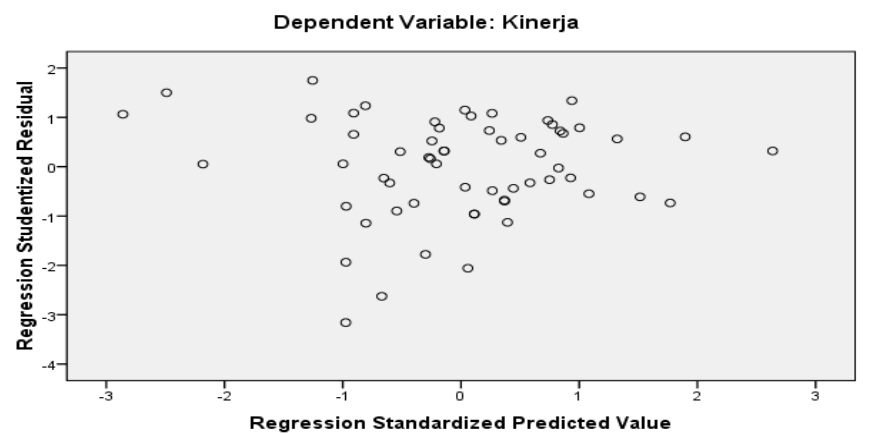

Gambar 1 Grafik Scatterplot

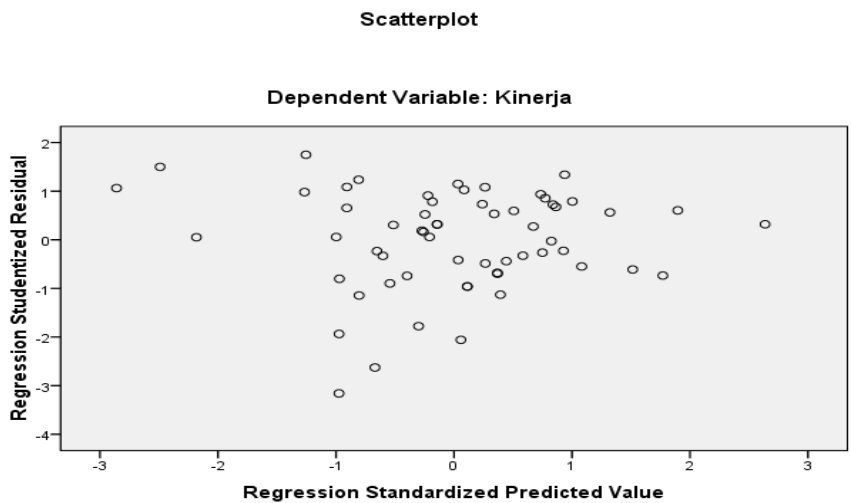

Gambar 2 Grafik Normal P-P plot

Tabel 2

Hasil Estimasi Regresi

\begin{tabular}{|ll|r|r|r|r|r|}
\hline \multirow{2}{*}{ Model } & \multicolumn{2}{|c|}{$\begin{array}{c}\text { Unstandardized } \\
\text { Coefficients }\end{array}$} & $\begin{array}{l}\text { Standardized } \\
\text { Coefficients }\end{array}$ & \multicolumn{2}{|c|}{} \\
\cline { 2 - 7 } & \multicolumn{1}{c|}{ B } & Std. Error & \multicolumn{1}{|c|}{ Beta } & \multicolumn{1}{c|}{ t } & \multicolumn{1}{c|}{ Sig. } \\
\hline $1 \quad$ (Constant) & -10.270 & 2.762 & & -3.718 & .000 \\
Gaya Kepemimpinan & .643 & .084 & .537 & 7.669 & .000 \\
Kompensasi & .258 & .052 & .335 & 5.008 & .000 \\
& & & & & \\
\hline
\end{tabular}

a. Dependent Variable: Kinerja

Sumber Data Primer Diolah Tahun (2017)

Berdasarkan hasil uji heteroskedastisitas metode grafik scatterplot menunjukkan bahwa sebaran data penelitiancenderung menyebar tidak teratur dan tidak membentuk pola tertentu. Hal ini berarti tidak terjadi penyimpangan asumsi klasik heterokedastisitas pada model regresi yang dibuat, dengan kata lain menerima hipotesis homoskedastisitas.

\section{c. Uji Normalitas}

Uji Normalitas bertujuan untuk menguji apakah dalam model regresi, variabel bebas dan variabel terikat, keduanya terdistribusikan secara normal ataukah tidak. 
Dari gambar 2 tersebut terlihat bahwa sebaran jawaban responden terdistribusi secara normal.

Grafik histogram sebagaimana dalam Gambar 2 menunjukkan bahwa bentuk grafik seperti lonceng terbalik. Hal tersebut menunjukkan distribusi data penelitian berdistribusi normal. Grafik normal P-P Plot menunjukkan sebaran data menyebar di sekitar garis diagonal. Hal tersebut menunjukkan distribusi data penelitian berdistribusi normal.

\section{Hasil Uji t (Pengujian Hipotesis Secara Parsial)}

Uji t dimaksudkan untuk mengetahui signifikansi pengaruh secara parsial dari variabel-variabel bebas $(\mathrm{X})$ terhadap variabel tergantung (Y). Hasil uji hipotesis dengan bantuan salah satu program statistik disajikan dalam Tabel 3.

Berdasarkan tabel dapat diketahui persamaan regresi yang terbentuk adalah:

$$
Y=-10,270+0,643 X 1+0,258 \times 2
$$

Keterangan:

$\mathrm{Y}=$ Kinerja karyawan

$\mathrm{X} 1=$ Gaya kepemimpinan

$\mathrm{X} 2=$ kompensas

Berdasarkan Tabel 3 dapat disimpulkan bahwa dari nilai thitung ditunjukkan bahwa:

\section{a. Uji Hipotesis 1 (H1)}

Perumusan hipotesis:

Ho : $\beta=0$; tidak terdapat pengaruh yang signifikan secara parsial antara gaya kepemimpinan terhadap kinerja karyawan.

Ha : $\beta \neq 0$; terdapat pengaruh yang siginfikan

secara parsial antara gaya kepemimpinan terhadap kinerja karyawan

Daritabel 3 bahwa variabel gaya kepemimpinan $\left(\mathrm{X}_{1}\right)$ memiliki nilai thitung sebesar 7,669 lebih besar dari nilai tabel sebesar 2,002 $(\mathrm{df}=\mathrm{n}-2)$. Hal tersebut dipertegas dengan nilai probabilitas sebesar 0,000 lebih kecil dari 0,05 sebagai taraf yang telah ditetapkan. Hasil uji statistik tersebut menunjukkan bahwa Hipotesis diterima yang berarti secara parsial variabel gaya kepemimpinan $\left(\mathrm{X}_{1}\right)$ berpengaruh signifikan terhadap kinerja karyawan (Y).

\section{b. Uji Hipotesis 2 (H2)}

Perumusan hipotesis:

Ho : $\beta=0$; tidak terdapat pengaruh yang signifikan secara parsial antara kompensasi terhadap kinerja karyawan.

$\mathrm{Ha}: \beta \neq 0$; terdapat pengaruh yang siginfikan secara parsial antara kompensasi terhadap kinerja karyawan

Dari tabel 3 bahwa kompensasi $\left(\mathrm{X}_{2}\right)$ memiliki nilai thitung sebesar 5,008 lebih besar dari nilai tabel sebesar 2,002 ( $\mathrm{df}=\mathrm{n}-2)$. Hal tersebut dipertegas dengan nilai probabilitas sebesar 0,000 lebih kecil dari 0,05 sebagai taraf yang telah ditetapkan. Hasil uji statistik tersebut menunjukkan bahwa Hipotesis diterima yang berarti secara parsial variabel kompensasi $\left(\mathrm{X}_{2}\right)$ berpengaruh signifikan terhadap kinerja karyawan (Y).

Dari perhitungan uji $t$ untuk variabelvariabel gaya kepemimpinan $\left(\mathrm{X}_{1}\right)$, kompensasi $\left(\mathrm{X}_{2}\right)$ terhadap kinerja karyawan (Y), menunjukkan bahwa semua nilai thitung lebih besar dari $t_{\text {tabel }}\left(t_{\text {hitung }}>t_{\text {tabel }}\right)$ dan signifikansi lebih kecil dari 0,05 $(p<0,05)$. Dengan demikian hipotesis 1,2 dapat diterima dan terbukti kebenarannya.

\section{Uji F (Pengujian Hipotesis Secara}

\section{Simultan)}

Pengujian hipotesis dalam penelitian ini digunakan uji $F$, yaitu untuk menguji pengaruh gaya kepemimpinan dan kompensasi berpengaruh signifikan terhadap kinerja karyawan.. Hasil uji hipotesis dengan bantuan salah satu program statistik disajikan 
dalam Tabel 4 .

Berdasarkan perhitungan pada tabel 4 diketahui nilai $F_{\text {hitung }}=72,713$ lebih besar dari nilai $\mathrm{F}_{\text {tabel }}$ yaitu sebesar 2,769 $\left(d f_{1}=3\right.$; $\left.d f_{2}=56 ; \alpha=5 \%\right)$. Hal tersebut juga ditunjukkan dengan nilai signifikansi yang dihasilkan yaitu sebesar 0,000 jauh lebih kecil dari 0,05 sebagai taraf yang telah ditetapkan. Hasil uji statistik tersebut berarti bahwa gaya kepemimpinan dan kompensasi berpengaruh signifikan terhadap kinerja karyawan. Dengan demikian dapat dinyatakan bahwa Hipotesis dapat terbukti kebenarannya.

Tabel 2.Hasil Uji F (Simultan)

ANOVA $^{b}$

\begin{tabular}{|c|c|c|c|c|c|c|}
\hline \multicolumn{2}{|c|}{ Model } & Sum of Squares & $d f$ & Mean Square & $\mathrm{F}$ & Sig. \\
\hline \multirow[t]{3}{*}{1} & Regression & 1506.625 & 3 & 502.208 & 72.713 & $.000^{\mathrm{a}}$ \\
\hline & Residual & 386.775 & 56 & 6.907 & & \\
\hline & Total & 1893.400 & 59 & & & \\
\hline
\end{tabular}

a. Predictors: (Constant),Kompensasi, Gaya Kepemimpinan

b. Dependent Variable: Kinerja

Sumber Data Primer Diolah Tahun (2017)

Tabel 3. Hasil Uji t (Parsial)

Coefficients $^{a}$

\begin{tabular}{|l|r|r|c|r|r|}
\hline \multirow{2}{*}{ Model } & \multicolumn{2}{|c|}{$\begin{array}{c}\text { Unstandardized } \\
\text { Coefficients }\end{array}$} & $\begin{array}{l}\text { Standardized } \\
\text { Coefficients }\end{array}$ & \multicolumn{2}{|c|}{} \\
\cline { 2 - 7 } & \multicolumn{1}{c|}{ B } & Std. Error & Beta & \multicolumn{1}{|c|}{ Sig. } \\
\hline $1 \quad$ (Constant) & -10.270 & 2.762 & & -3.718 & .000 \\
Gaya Kepemimpinan & .643 & .084 & .537 & 7.669 & .000 \\
Kompensasi & .258 & .052 & .335 & 5.008 & .000 \\
& & & & & \\
\hline
\end{tabular}

a. Dependent Variable: Kinerja

Sumber Data Primer Diolah Tahun (2017)

Tabel 4. Hasil Uji Determinasi

Model Summary ${ }^{b}$

\begin{tabular}{|l|r|r|r|r|}
\hline Model & $\mathrm{R}$ & $\mathrm{R}$ Square & Adjusted R Square & Std. Error of the Estimate \\
\hline 1 & $.892^{\mathrm{a}}$ & .796 & .785 & 2.62806 \\
\hline
\end{tabular}

a. Predictors: (Constant)Kompensasi, Gaya Kepemimpinan

b. Dependent Variable: Kinerja

Sumber Data Primer Diolah Tahun (2017)

\section{Hasil Uji Koefisien Determinasi $\left(\mathbf{R}^{\mathbf{2}}\right)$}

Uji determinasi dilakukan untuk mengetahui besarnya pengaruh variabel gaya kepemimpinan, kompensasi dan efektivitas pelatihan terhadap kinerja karyawan. Uji determinasi dalam penelitian ini dapat dideteksi dengan nilai adjusted $R$ square yang dihasilkan oleh model regresi. Hasil uji determinasi disajikan dalam tabel 5. 
Berdasarkandata dalam Tabel 5 diketahui bahwa nilai adjusted $\mathrm{R}$ square sebesar 0,785 setara dengan 78,5\%. Hal tersebut berarti bahwa variabel bebas yang terdiri dari gaya kepemimpina dan kompensasi memiliki pengaruh terhadap kinerja karyawansebesar 78,5\%. Hasil determinasi tersebut menunjukkan bahwa variabel bebas memiliki pengaruh terhadap variabel terikatnya sebesar $78,5 \%$, sedangkan sisanya yaitu sebesar $21,5 \%$ dipengaruhi oleh variabel lain yang tidak dibahas dalam penelitian ini.

Dari hasil analisis tersebut diatas dapat dijelaskan bahwa gaya kepemimpinan dalam hal ini gaya demokratik yang di aplikasikan oleh pimpinan PT. Finansia Multi Finace Cabang Banjarmasin sudah merupakan gaya yang disukai oleh sebagian besar karyawannya, ditambah dengan pemberian kompensasi yang terbagi menjadi kompensasi langsung dan tidak langsung yang diberikan oleh perusahaan secara baik dan sudah sesuai dengan keinginan karyawannya, sejalan dengan meningkatnya kinerja karyawan.

\section{KESIMPULAN DAN SARAN}

Berdasarkan hasil penelitian ini dapat disimpulkan hal-hal sebagai berikut:

1. Gaya kepemimpinan mempengaruhi kinerja karyawan PT. Finansia Multi Finance Cabang Banjarmasin

2. Kompensasi mempengaruhi kinerja karyawan PT. Finansia Multi Finance Cabang Banjarmasin

Secara bersama-sama gaya kepemimpinan kompensasi dan efektifitas pelatihan yang diberikan perusahaan mempengaruhi kinerja karyawan PT. Finansia Multi Finance Cabang Banjarmasin

\section{DAFTAR PUSTAKA}

Aunillah, 2005 AnalisisKompensasidanMotivasiKerjat erhadapPrestasiKerja

Guru Madrasah AliyahNegeriSidoarjo, TesisPascasarjana UMY, tidakdipublikasikan.

Basri. dan Veithzal Rivai. 2005. Performance Apprasial : Sistem Yang Tepat

Untuk Menilai Kinerja Karyawan \& Meningkatkan Daya Saing

Perusahaan. Jakarta: PT. Raja Grafindo Persada.

Basuki, dan Indah Susilowati. 2005. Dampak Kepemimpinan, dan Lingkungan

Kerja, Terhadap Semangat Kerja. Jurnal JRBI. Vol 1. No 1. Hal: 31-47.

Cahyono, Budhi. dan Suharto. 2005. Pengaruh Budaya Organisasi,

Kepemimpinan, dan Motivasi Kerja, Terhadap Kinerja Sumber Daya

Manusia Di Sekretariat DPRD Propinsi Jawa Tengah. Jurnal JRBI. Vol 1.

No 1. Hal: 13-30.

Dessler, Garry. 2006. Manajemen Sumber Daya Manusia. Jakarta: Indeks.

Ghozali, Imam. 2005. Aplikasi Analisis Multivariate dengan Program SPSS.

Semarang: Badan Penerbit Universitas Diponegoro.27

Hasibuan, Malayu SP, 2010. Manajemen Sumber Daya Manusia Edisi Revisi. Jakarta:Bumi Askam

Handoko, T. Hani, 2008. Manajemen Personalia dan Sumber Daya Manusia Edisi 2. Yogyakarta:BPFE

Simamora, Henry, 2004. Manajemen Sumber Daya Manusia. Yogyakarta. Penerbit Sekolah Tinggi ekonomi YKPN. 